\title{
LÍNGUA(GENS), MÍDIA(S) E PODER SOB A ÓTICA DISCURSIVA FOUCAULTIANA ${ }^{1}$
}

Entrevista com Maria do Rosário Gregolin

Languages, medias and power under Foucauldian discursive optic

\author{
Maria do Rosário Gregolin ${ }^{2}$ \\ Universidade Estadual Paulista - UNESP-FCLAr
}

\begin{abstract}
RESUMO: Nesta entrevista, a pesquisadora e professora Maria do Rosário Gregolin discorre sobre as contribuições da Análise do Discurso foucaultiana para o ensino da língua e para a produção e circulação de textos na atualidade. A linguista nos lembra que a língua pode funcionar como um instrumento de poder, porque por ela tanto se pode oprimir quanto se emancipar. Ademais, discute a relevância das leituras foucaultianas para a constituição da Análise do Discurso (AD) no Brasil, perspectiva teórica que questionou tanto a tradição gramatical quanto a tradição de análise estrutural da língua, dominantes então no país, em um contexto histórico de declínio do governo repressivo da Ditadura Militar (19641985). Além dessa contextualização histórica da $\mathrm{AD}$ e da importância da obra foucaultiana, a linguista aborda em seus estudos diferentes dispositivos que atuam no controle de nossas práticas e na produção de nossas identidades. Entre eles, ela tem se dedicado às novas mídias digitais, seus usos e seus impactos na atualidade, responsáveis por uma maior produção e difusão de conteúdos adulterados, com a banalização das chamadas fake news, o que nos impõe o necessário debate sobre esses dispositivos discursivos e seu papel na construção da(s) verdade(s).

Palavras-chave: Análise do Discurso; Michel Foucault; Relações de poder; Mídia Digital; Ensino de língua.
\end{abstract}

\begin{abstract}
In this interview, the researcher and professor, Maria do Rosário Gregolin discusses about the Foucauldian Discourse Analysis contributions to the language teaching and to the production and circulation of texts nowadays. The linguist reminds us that language can function as an instrument of power, because through it you can oppress and emancipate. Furthermore, she discusses the relevance of Foucauldian readings to the constitution of the Discourse Analysis (AD) in Brazil, a theoretical perspective that questions both grammatical tradition
\end{abstract}

\footnotetext{
${ }^{1}$ Entrevista realizada no dia 12 de setembro de 2018, durante o V CIAD - Colóquio Internacional de Análise do Discurso: Discurso e (pós)verdade. Efeitos de real e sentidos da convicção. Na ocasião, a entrevistada proferiu a conferência "Assim falou Foucault: a verdade é historicamente construída e estrategicamente localizada...”. A equipe responsável pela produção, transcrição, retextualização e revisão desta entrevista foi composta por Andréia M. Santana, Bianca C. O. Fabiano, Bruno Ortega, Evandro Paschoalino, João Victor Dantas, Karen Naomi Aisawa e Raquel Casare, discentes no curso de Bacharelado em Linguística da UFSCar, e Luzmara Curcino, docente no Departamento de Letras e no Programa de Pós-graduação em Linguística da Universidade Federal de São Carlos (DL/PPGL/UFSCar).

2 Doutora em Linguística e Língua Portuguesa, professora livre-docente em Análise do Discurso junto à Universidade Estadual Paulista "Julio de Mesquita Filho", campus de Araraquara (UNESP/FCLAr), pesquisadora e líder do GEADA - Grupo de Estudos em Análise do Discurso de Araraquara. Entre suas principais publicações destacam-se os livros Foucault e Pêcheux na Análise do Discurso - diálogos e duelos (2004); e Discurso e mídia - a cultura do espetáculo (2003), ambos pela Editora Claraluz.
} 
and the structural language analysis tradition, later dominant in the country, all of this in a specific historical context: the decline of the Military Dictatorship repressive government (1964-1985). In addition to this historical contextualization of the Discourse Analysis and the importance of the Foucauldian work in its consolidation, the interviewed show us, with her studies, that society is controlled by some devices, and among them she discusses the role of the new media in the process of identity construction, considering that new techniques of textual production and circulation bring about remarkable changes in social relations. Finally, the researcher reflects about one of the consequences of these new media techniques, the responsible for a greater diffusion of adulterated content, in an expansion of production, and consequently a trivialization of so-called fake news and other forms of misrepresentation of the truth(s).

Keywords: Discourse analysis; Foucault; Power relations; Digital media; Language. 


\section{Língua, Ensino e Poder}

Entrevistadores: Você tem um notável trabalho dedicado aos livros didáticos e ao ensino ${ }^{3}$, assim como foi a responsável pela difusão no Brasil das obras de Michel Foucault no campo dos estudos da linguagem, em especial na Análise do Discurso. Em que medida as reflexões desse filósofo contribuíram para suas pesquisas, em especial, aquelas ligadas ao ensino?

Maria do Rosário Gregolin: Segundo a perspectiva foucaultiana, que eu venho há muito adotando em meus trabalhos, a língua é concebida como uma forma de expressão de poder, como um instrumento de poder. O ensino da língua no Brasil, até o final dos anos 1970, era centrado no ensino normativo da gramática e de uma metalinguagem tecnicista. Embora houvesse atividades de leitura e produção de texto, não havia condições para o ensino da leitura crítica, para o ensino da produção de textos críticos, devido ao contexto de repressão política que inviabilizava a abordagem de certos temas, discussões, reflexões no espaço institucional da escola. Com a abertura política no país e com a ampliação e maior difusão de certos princípios da Linguística, em especial das ideias da Sociolinguística e da Análise do Discurso, inicia-se um processo de mudança na forma de se conceber o ensino da língua materna. Essas abordagens contribuem para preconizar tanto a priorização do trabalho com diferentes textos quanto uma inversão do olhar em relação às diferenças linguísticas, às variações linguísticas, até então vistas como algo que deveria ser "corrigido", e que passam a ser assumidas como fenômenos próprios da língua, dignos de serem descritos e compreendidos em seu funcionamento. É o momento em que se começa a discutir a questão do preconceito linguístico, suas origens diversas e sua difusão.

Até os anos 70, só as classes mais privilegiadas socioeconomicamente iam para a escola. A partir de então ocorre uma expansão do ensino público, possibilitando a inserção de outras classes sociais nessa instituição e, com isso, aumenta sensivelmente a presença de uma maior diversidade linguística. $\mathrm{O}$ ensino da língua, até então centrado na modalidade escrita, na promoção da norma culta e formal, confundida com "a" língua portuguesa, e no domínio de uma metalinguagem oficial, foi confrontado com os novos aportes do campo de estudos da Linguística, responsáveis por uma abordagem mais descritiva, científica e inclusiva dos usos linguísticos. As discussões alimentadas por essa nova abordagem, e sua consequente denúncia dos preconceitos linguísticos, vão abrir a possibilidade à diversidade linguística e à

\footnotetext{
${ }^{3}$ Cf. Gregolin (1993a; 1993b; 1998; 2001), entre outros.
} 
necessidade das escolas trabalharem prioritariamente com o texto, com as habilidades de leitura e de produção escrita de textos, para a formação de um leitor mais crítico e de sujeitos capazes de produzir textos variados, também críticos. Minha atuação inicial, como pesquisadora, professora e linguista analista do discurso se insere nesse contexto. Do interior dos estudos linguísticos segui desenvolvendo livros didáticos e ministrando muitos cursos de capacitação de professores.

Foi preciso muito tempo para que se formulassem os Parâmetros Curriculares Nacionais, publicados apenas no final dos anos 90, nos quais se iria tematizar formal e institucionalmente essa ideia das relações de poder na/pela língua e da necessidade de se formar um aluno que seja capaz de produzir um discurso público, que saiba se colocar de modo a não ser desqualificado por pertencer às classes conhecidas como subalternas, que compreenda o poder da tomada de palavra, do dizer, e que o exerça plenamente. Esse deve ser o objetivo da escola, do ensino, de modo geral, e do ensino de língua, de modo específico.

Após o golpe, em 2016, responsável pela destituição da presidenta eleita Dilma Rousseff, é possível constatar um rápido retrocesso no plano educacional, de início com a retirada de pessoas progressistas do poder - e não estou me referindo apenas ao âmbito político-partidário, mas sobretudo aos pensadores e educadores que atuavam no campo das políticas públicas de educação ou que eram uma referência nesse campo e que passam a ser sistematicamente dispensados e criticados -, levando-nos a pensar na perigosa possibilidade de todas as nossas vitórias na educação, nos últimos anos, se perderem.

Iniciei dizendo que a língua é um instrumento de poder. Disse isso, inspirada nas ideias de Foucault, porque o modo como é ensinada, assumida pela escola, reflete os modos como o poder se exerce em uma sociedade. Assim, se "o que" se ensina sobre a língua e o modo como isso é feito é uma forma de exercer poder, é preciso que disponhamos de uma teoria que nos ajude a pensar nessas relações de poder e o quanto ele está entrelaçado com o saber. A partir dessa perspectiva, somos levados a pensar em que medida se impede, por exemplo, que determinados grupos sociais se apropriem desse instrumento de poder, que é a língua, ou do saber legitimado sobre a língua, afastando-os justamente de seu direito à cidadania e dos direitos que a cidadania pode lhes outorgar, frutos de lutas e das conquistas hoje colocadas em xeque. Esse é um grande problema, não só do ensino fundamental e médio, mas também do superior: reconhecer o papel da língua e do discurso em sua força simbólica na nossa sociedade e garantir esse saber, como forma de poder, a todos, indistintamente.

Foucault é bastante conhecido pelos estudiosos das áreas de Filosofia, História e Sociologia, e reconhecido como tal, embora ele negasse esses títulos de filósofo, historiador 
ou sociólogo. Em sua verve provocadora, ele dizia ser um pirotécnico, porque queria causar pequenas explosões em cada área do saber. Não sem razão, para ele, a teoria deveria servir para derrubar muros. O que nós, no GEADA ${ }^{4}$, com a leitura que realizamos desse autor, com a divulgação e incorporação de suas ideias no campo dos estudos linguísticos no Brasil e com a difusão de sua abordagem dos discursos, buscamos fazer é garantir que suas ideias, que suas teorias continuem nos auxiliando a derrubar certos muros antigos e aqueles que são levantados atualmente, atuando nesse campo dos estudos da língua(gem), e refletindo sobre a "ordem dos discursos", sobre as coerções sobre o dizer e o interpretar, sobre as formas de poder que elas implicam, sobre os dispositivos que constituem os regimes de verdade de nosso tempo presente.

\section{A Ordem do Discurso}

Entrevistador: Em relação à linguagem, e sua ligação com o poder, a que tipo de "pirotecnia" poderíamos recorrer no campo dos estudos linguísticos inspirados nas ideias do filósofo?

Maria do Rosário Gregolin: Como mencionei anteriormente, Foucault é mais conhecido nos campos da Filosofia, da História, da Sociologia, e também da Educação, mas ele tem em toda a sua obra uma reflexão sobre o discurso, incluindo sua aula inaugural no Collège de France, a instituição de ensino superior mais respeitada da França. Nessa aula famosa, ele discorre sobre a ordem do discurso ${ }^{5}$, em um texto magistral, proferido para um público amplo, composto também de intelectuais e grandes pensadores do início dos anos 70. Nela, aborda os poderes e perigos de falar, de tomar a palavra, e discute, entre as coerções que instauram esse poder e esse perigo do discurso, o constante constrangimento e tutela do que enunciamos e que são exercidos por parte das instituições, a partir das quais nossos dizeres podem ganhar força, valor, existência, ou serem apagados e esquecidos.

Estar naquela instituição, naquela situação formal e ritualizada de fala, e usar aquele momento para refletir justamente sobre o poder em relação ao discurso que as instituições, os

\footnotetext{
${ }^{4}$ GEADA - Grupo de Estudos de Análise do Discurso de Araraquara, criado e coordenado, há quase três décadas, pela Profa. Dra. Maria do Rosário Gregolin, junto ao Programa de Pós-Graduação em Linguística e Língua portuguesa da UNESP/FCLAr, com o objetivo de discutir as bases epistemológicas e teóricometodológicas da Análise do Discurso, fundamentada, principalmente, nos pensamentos de Michel Foucault. Para mais informações, acessar o site oficial do grupo, disponível em: 〈http://geadaararaquara.blogspot.com/〉.

${ }^{5}$ Cf. Foucault (1996).
} 
rituais, os dispositivos exercem sobre os sujeitos que falam e sobre a recepção daquilo que os sujeitos falam demonstra a ousadia de Foucault e o caráter intrigante de suas ideias e posturas. Ele, nessa aula, explicita uma série de mecanismos de controle dos discursos, o que é próprio a toda e qualquer sociedade, e demonstra como esses mecanismos são responsáveis pela produção da verdade, do dizer verdadeiro, que fazem das vontades de verdade de um certo grupo, de um certo espaço e momento histórico, o equivalente à "verdade".

A título de exemplo, analisando a história do Direito ${ }^{6}$, Foucault aborda a ritualística do discurso jurídico, os seus protocolos, suas regularidades e observa como seu funcionamento é regrado por meio de uma dada retórica, de certos procedimentos retóricos de disputa e estabelecimento de 'verdades', constituindo assim uma forma de poder, de um poder durável, de um poder que se exerce pelo domínio da palavra, de um poder responsável pela formação de determinadas elites políticas, desde a Grécia Antiga, e que perduram até hoje. Ele o fez também em relação a outros campos do saber, como o da Medicina ${ }^{7}$. A potência pirotécnica de sua reflexão sobre o discurso e sobre a linguagem está presente em toda a sua obra.

Nesse sentido, sua teoria, suas ideias e o modo como as expõe produzem essas 'explosões' que pretendia. Isso não se deu de forma diferente no campo da Linguística brasileira. Introduzida no país nos anos 70 por, entre outros pesquisadores, Mattoso Câmara ${ }^{8}$ - que representava a linguística formal, estrutural e descritiva -, a disciplina Linguística se dedicou à importante descrição do sistema da língua portuguesa empregada no Brasil e de seu funcionamento, o que significou metodologicamente não abordar certos fatores extralinguísticos, da ordem do social e do histórico, por exemplo. A reintrodução e a problematização dessas dimensões foram uma das contribuições de Foucault para se pensar a língua em sua complexidade, a relação da língua com o poder e dela com os sujeitos, enfim, a relação da língua com o discurso.

O discurso é, tal como concebido em AD, e afirmado por Michel Pêcheux ${ }^{9}$, ao mesmo tempo, "estrutura" e "acontecimento". Isso implica dizer que, em sua atualização, em seu uso efetivo pelos sujeitos, o que é dito, o que é enunciado se manifesta sob a forma da língua, em seu funcionamento formal e material, e essa sua atualização envolve relações de poder e tem uma historicidade. Então, quando a Análise do Discurso começou a ser desenvolvida no Brasil - e, com isso, a leitura de Michel Foucault, de Michel Pêcheux e de Mikhail Bakhtin,

\footnotetext{
${ }^{6}$ Cf. Foucault (1999).

${ }^{7}$ Cf. Foucault (1984).

8 Dentre suas principais obras de linguística, destacam-se Para o estudo da fonêmica portuguesa (1953) e Dicionário de Lingüística e Gramática: referente à língua portuguesa (1968).

${ }^{9}$ Cf. Pêcheux (1997).
} 
todos eles com nuances muito fortes de ideologias marxistas -, ela entra em conflito com as abordagens gramaticais mais tradicionais e com a teorias linguísticas de base estrutural que tinham se tornado mais recentemente dominantes e que eram ensinadas especialmente nos cursos de Letras no Brasil. Entre as 'explosões' produzidas no campo de estudos linguísticos no Brasil, com a leitura desses autores, e em nosso caso, no GEADA, com a leitura de Foucault, destacamos não apenas a difusão das ideias desse campo da $\mathrm{AD}$ a partir dos anos 80, de modo a estabelecer um espaço institucional importante para o conhecimento produzido a partir dessa perspectiva, como também a produção de uma certa instabilidade dos muros erigidos pela Linguística institucional, oficial, em exercício até então, que, mesmo sem ter tido essa pretensão, era em certa medida "adequada" quanto ao tipo de conteúdo possível de ser visto acerca da língua durante o período de governo repressivo, da Ditatura civil e militar no Brasil, uma vez que, enquanto se propunha a pensar a imanência e as estruturas da língua portuguesa, ocupava o espaço que poderia ser dedicado a discutir outras questões, de ordem sociopolítica, concernentes à língua.

\section{Mídias e a formação de identidades}

Entrevistador: Outra frente comum de seus trabalhos de pesquisa, de diversos artigos que escreveu até hoje $\mathrm{e}^{10}$, é aquela em que você trata da mídia como uma instância de produção da história do presente, responsável por acontecimentos discursivos que tensionam a memória e o esquecimento, produzindo assim certas identidades. Como a mídia exerce esse papel e que impacto ela tem sobre a formação de nossas identidades?

Maria do Rosário Gregolin: Para tratarmos desse assunto, precisaremos olhar historicamente para a nossa sociedade no mundo Ocidental, que desde o século XVI, como consequência da invenção da imprensa, passa por um processo cultural de ampliação dos tipos e do alcance das mídias responsáveis pela comunicação e estabelecimento da informação. Assim, tem início um processo de construção de uma sociedade da informação com base em uma cultura tipográfica, com base na escrita e na leitura de impressos.

A partir do final do século XIX, surgem novas tecnologias de comunicação e de registro da informação, tais como o telégrafo, a fotografia e o telefone. Tudo isso vai ampliar

${ }^{10}$ Cf., entre outros artigos, Gregolin (2007a; 2007b). 
as possibilidades de estabelecimento da comunicação à distância, já instauradas com a invenção da escrita, com a diferença de que essa comunicação a partir de então se torna instantânea, simultânea, ao 'vivo'. Quando afirmamos que as nossas identidades são formadas por essas mídias, é porque sua criação e sua difusão ocasionam mudanças, algumas de grande importância, nas relações sociais.

A passagem de uma cultura tipográfica, impressa, centrada na escrita, para uma cultura visual e de interlocução simultânea, constitui um novo tipo de intimidade e novas formas de sociabilidade. As mídias formatam nossas identidades dada a possibilidade que geram de se poder enxergar mais, melhor, além do que poderia ser visto normalmente, de se poder ouvir além do que o ouvido humano é capaz de captar. Assim, ver o que antes não se via e falar à distância, simultaneamente, produz novas subjetividades, novas formas de ser e de estar no mundo. Por isso, a mídia representa talvez o principal dispositivo de agenciamento das subjetividades na atualidade.

Eu escrevi mais recentemente um artigo, que se encontra disponibilizado na Revista Moara $^{11}$, de Belém (PA), sobre o dispositivo escolar no Brasil. Mobilizei para isso o conceito de "dispositivo" proposto por Michel Foucault. Para ele, toda e qualquer sociedade é controlada por certos dispositivos. A escola, por bastante tempo, desempenhou o importante papel como dispositivo de formatação das nossas identidades, como dispositivo e como parte

[...] de um dispositivo de saber e de poder em nome das exigências históricas de construção da identidade nacional, com base nos ideais positivistas de ordem, progresso, higiene, civilidade etc. A instalação desse dispositivo coincidiu com o início da ampliação dos usos sociais da fotografia no Brasil. Muitas instituições produziram suas imagens fotográficas e fixaram uma memória iconográfica dos espaços escolares e das práticas discursivas desenvolvidas no interior dessa rede de saber e de poder (GREGOLIN, 2015, p. 6).

Nesse meu trabalho eu analiso justamente uma série de fotografias feitas no interior de ambientes escolares e reflito sobre o modo como sua arquitetura, sua organização dos espaços, seu mobiliário, podem formatar as identidades, inclusive as de gênero. Por exemplo, encontram-se fotos dos meninos em aulas de marcenaria, de tiro - porque a República era militarista -, e das meninas em aulas de economia doméstica, de culinária e de balé. $\mathrm{O}$ registro dessas informações imagéticas, a difusão dessas imagens, abriram a porta para o "imaginário" sobre a sociedade que ali se formava. A arquitetônica desses espaços que

${ }^{11}$ Cf. Gregolin (2015). 
conformava esses corpos é então representada nessas fotografias, quanto a seu modo de ser e estar em uma dada sociedade, e seus valores dominantes.

'Novas' mídias passam a assumir esse papel que outrora fora exercido por instituições como as escolares. Elas formam as identidades porque elas invadem o nosso cotidiano. Se antes o dispositivo escolar era mais fechado, mais localizado, mais institucionalizado, com as tecnologias da fotografia, do cinema e da televisão, tem-se uma ação muito mais direta sobre a produção de "kits" de identidade. A mudança mais repentina acontece entre os anos de 1990 e 2000, quando passamos da televisão para o computador, e depois para a web. Essa rápida mudança nos deixa atordoados, de modo que se torna difícil enxergar o tempo presente e avaliar esse atordoamento - sua extensão, razões e consequências - produzido pela lógica do volume, do excesso, da fluidez, da obsolescência. É como se tudo ficasse velho muito rapidamente.

No âmbito acadêmico tem-se falado sobre uma etnografia da web, uma metodologia que nos possibilitaria estudar esses textos que circulam na internet, uma vez que eles envelhecem e são descartados com tamanha velocidade que, às vezes, não dá tempo de colhêlos para estudo, estabelecê-los em conjuntos que permitam sua melhor compreensão. Outra mudança, essa de âmbito mais pessoal, é aquela responsável pela promoção de um tipo peculiar de solidão: seja a solidão efetiva, diante de nossos dispositivos eletrônicos em casa, seja a solidão na multidão, uma vez que aparentemente todo mundo está junto nos bares, na sala de aula, mas as pessoas estão com o celular na mão, o tempo todo, como se se encontrassem em lugares diferentes.

Voltando à questão das identidades, imagine o poder das redes sociais para formatar a identidade hoje em dia. Temos, por exemplo, tutoriais de moda que padronizam a beleza, colocando em evidência certas formas específicas de beleza, tal como a representação majoritária da modelo branca, ocidental e jovem, excluindo outros tipos de beleza e assim estabelecendo hierarquias, constituindo gostos e formas de consumo.

\section{Mídias digitais e a produção de verdade}

Entrevistador: A circulação virtual, por meio de novos dispositivos de uso cada vez mais individuais, assim como a velocidade com que as coisas são descartadas, impacta sobre a produção das notícias e informações. Em que medida essas mudanças nas formas de produção e circulação dos textos afetou também a qualidade e a veracidade das informações? 
Maria do Rosário Gregolin: Essa possibilidade de forjar, de falsificar notícias e textos não é de hoje. Ela sempre foi possível e exercida, em cada tempo com as tecnologias disponíveis. Um exemplo, nem tão distante temporalmente de nós, é o do cinema: Leni Riefenstahl, famosa cineasta nazista, em seu filme "O triunfo da vontade", de 1935, tinha tamanho domínio sobre a técnica do cinema que conseguiu produzir um filme de propaganda, ficcional, como se fosse um documentário, como o registro do $6^{\circ}$ Congresso do Partido Nazista, realizado em Nurenberg, em 1934. Para recriar o evento, contou com milhares de figurantes. O "documentário" valeu-se de uma linguagem romântica para exaltar, endeusar a figura de Hitler e para simular o seu encontro com as pessoas do povo que o amavam, de modo a promovê-lo como mito. Além do uso das técnicas e tecnologias de produção e reprodução de textos e imagens que constroem a realidade de que falam, manipulam, exagerando ou edulcorando, tal como no caso deste filme, também vemos hoje emergirem, em meios e com técnicas diversas, discursos negacionistas, que negam a própria existência do Holocausto.

No Brasil, atualmente, vemos emergir discursos que negam a repressão covarde e sistemática, a prática da tortura, os assassinatos e desaparecimentos dos corpos de cidadãos brasileiros, crimes de Estado que foram cometidos durante a Ditadura Militar (1964-1985). Além desses discursos negacionistas, vemos alguns que legitimam essas ações e as justificam. À vista disso, percebemos que a possibilidade de forjar textos e de construir "verdades" alternativas sempre existiu. O caso do Bacuri [Eduardo Collen Leite], militante da resistência contra a Ditadura no Brasil, é emblemático disso. Ele foi preso e torturado durante longos e dolorosos 110 dias, por torturadores célebres, os militares Sérgio Fleury e Brilhante Ustra. Depois disso, eles forjaram sua morte: o levaram para uma rodovia, o balearam e o fotografaram em um veículo, e aquela viria a ser a foto que figuraria na notícia de sua morte no dia seguinte, nos jornais. Eles forjaram a notícia falsa de sua fuga da prisão e depois divulgaram a foto que eles mesmos produziram como se ela fosse a prova da "verdade" que inventaram. As testemunhas que estavam ali, outros policiais, viram a cena e hoje temos seus depoimentos sobre o que de fato aconteceu no evento e quais foram as estratégias utilizadas então pelo aparelho repressor, como a de forjar as cenas de morte dos presos políticos, produzir imagens, enfim, provas que os desobrigariam da responsabilidade de seus atos.

Assim, o desenvolvimento técnico e sua acessibilidade facilita e contribui para a produção de textos, para o emprego de imagens e para a produção de vídeos por profissionais mas também por amadores, com diferentes objetivos, o que transforma assim as formas de produção e circulação dos textos, bem como seu valor em nossa sociedade. Uma vez que grande parte de nós tem a ilusão de ser verdadeiro tudo o que é publicado, assim, tudo o que 
figura na web, inclusive informações que podem nos soar excessivamente inverídicas, pode, indistintamente, diante de um internauta desavisado, pouco preparado e bombardeado sistematicamente com um tipo de texto, parecer, a seus olhos, uma verdade.

As falsas notícias encontram assim um ambiente único. Elas se constituem de textos que 'pretendem' dizer a 'verdade', que se apresentam como enunciados fiáveis, e contam com a ideologia de apagamento, de esquecimento, de negação de determinadas realidades, de ofuscamento de determinadas lutas e formas de resistência, de distorção da verdade factual. Sempre houve a possibilidade de falsificação. Então, o que é que se transforma efetivamente com a emergência dessas novas tecnologias e mídias? Hoje, com a expansão das possibilidades técnicas de reprodutibilidade, com sua maior acessibilidade, essas produções deixam de ser exclusividade daqueles poucos que delas dispunham, e se disseminam rapidamente. Walter Benjamin ${ }^{12}$, em sua época, olhava para o cinema como um instrumento e uma possibilidade de produzir determinadas verdades. O domínio dessa mídia se concentrava nas mãos de poucas pessoas, de grandes cineastas. Com o advento da web, essa produção deixa de se restringir a poucas pessoas e se expande, hoje, com uma crescente e rápida disseminação de vídeos e imagens, de produções amadoras e outras nem tanto. E esse é o perigo: a proliferação, a disseminação sem controle de um instrumento capaz de produzir 'verdades'. Se Benjamin, nos anos 1930, já falava sobre o perigo do cinema e de como a reprodutibilidade técnica estaria corrompendo, deturpando [a realidade], imaginem se ele estivesse vivo hoje o que é que iria pensar sobre as possibilidades que se nos apresentam com as novas tecnologias digitais.

Henry Jenkins, autor da obra Cultura da Convergência (2009), analisa justamente isso. Ele diz "Venere no altar da Convergência", para dizer que, hoje, todos os meios convergem na web, e assim nunca se sabe o destino que o texto terá quando for disponibilizado online. Ele pode nunca ser lido, como pode ser reproduzido indefinidamente. Um exemplo desse funcionamento é aquele do jovem norte-americano que criou um blog satírico chamado "Beto é do Mal", no qual postou várias fotos utilizando a imagem de Beto, famoso personagem do programa infantil Vila Sésamo. Nesse blog, Beto era colocado, por exemplo, ao lado de personalidades como o presidente Bush, da atriz Pâmela Anderson, e outros, para produzir efeito cômico. Um dia esse rapaz o colocou junto com o Bin Laden, como brincadeira. Cerca de dois anos depois dessa postagem em seu blog, uma manifestação em favor do Bin Laden usa essa imagem. Os apoiadores montam cartazes com imagens do ex-líder da Al-Qaeda e,

\footnotetext{
${ }^{12}$ Cf. Benjamin (1987).
} 
dentre elas, empregam a fotomontagem com o personagem Beto. Vejam o destino das imagens que produzimos: alguém do Afeganistão chegou até o blog desse jovem, copiou essa imagem e a empregou em centenas de cartazes. Os produtores de Vila Sésamo, alarmados com a repercussão dessa imagem de seu personagem, entraram com um processo, alegando não terem nada a ver com o Bin Laden. Esse episódio, relatado por Jenkins em seu livro, é bastante exemplar do funcionamento das mídias digitais na era da convergência. Uma vez publicado algo, o destino da produção é bastante incerto: um rapaz posta uma montagem em seu blog, como uma brincadeira sem maiores consequências, e a imagem ganha o mundo com repercussão, com consequências graves, depois de seu uso em cartazes em uma manifestação islâmico-fundamentalista em favor do líder árabe.

Diante desse cenário, é preciso que haja uma formação mais qualificada, mais crítica, mais atual, que permita a formação de um leitor mais precavido, mais 'desconfiado' da autenticidade, da veracidade, da fiabilidade daquilo que lhe chega às mãos. Um leitor desconfiado é sempre um bom leitor. Deve-se objetivar, assim, uma formação específica dos leitores dessas novas modalidades de produção e circulação de textos no ambiente digital. É preciso ensinar a ler as imagens em movimento, assim como a fotografia, como um texto, e principalmente como um discurso, que é produzido, formulado segundo posicionamentos daqueles que estão em sua emergência e que sua circulação é responsável por sua visibilidade restrita ou ampla que pode impactar a sua recepção. Nesse sentido, o trabalho da professora de vocês, Luzmara Curcino, é muito importante, porque ela vem trabalhando com a análise das formas como os textos são construídos e o modo como essas formas buscam inscrever a leitura que deles deve ser feita e, ao mesmo tempo, formatar nossas práticas culturais. São essas formas dos textos e os discursos sobre a leitura, tal como ela trabalha, elementos responsáveis por construir as representações que fornecem os parâmetros de nossa identificação como leitores.

Assim, nossa intervenção, como professores, como linguistas, como analistas do discurso que estudam a linguagem, que tomam esses fenômenos contemporâneos como seus objetos de pesquisa, deve ser nesse sentido: o de formar leitores que compreendam o funcionamento dessas novas técnicas de produção e reprodução de textos, de vídeos, de imagens fixas, e essa dispersão e alteração das fontes e dos agentes que tradicionalmente produziam as notícias, disseminavam as informações. O desafio maior de nosso tempo é o de letrar digitalmente nossos alunos e as gerações por vir, é o de formar leitores críticos na era da (re)produção digital, é o de dotá-los de um olhar e de ferramentas intelectuais e materiais para que possam interpretar os textos em sua condição de 'monumentos' (para empregarmos um 
termo usado por Foucault) e fazê-lo de forma politizada e comprometida com o bem da maioria.

\section{Referências}

BENJAMIN, Walter. A obra de arte na era de sua reprodutibilidade técnica. In: Obras escolhidas I. São Paulo: Brasiliense, 1987.

CÂMARA Jr., Mattoso. Para o estudo da fonêmica portuguesa. Rio de Janeiro: Organização Simões, 1953.

CÂMARA Jr., Mattoso. Dicionário de Linguiística e Gramática: referente à língua portuguesa. 3 ed. São Paulo: J. Ozon Editor, 1968.

FOUCAULT, Michel. Microfísica do poder. São Paulo: Graal; 1984.

FOUCAULT, Michel. A ordem do discurso. São Paulo: LOYOLA, 1996.

FOUCAULT, Michel. A Verdade e as Formas jurídicas. Rio de Janeiro: Nau Ed., 1999.

GREGOLIN, Maria do Rosário. Linguística Textual e Ensino de Língua: construindo a textualidade na escola. Alfa - Revista de Linguística, São Paulo, v. 37, p. 23-32, 1993a. Disponível em: <https://periodicos.fclar.unesp.br/alfa/article/view/3930>. Acesso em: 6 nov. 2019.

GREGOLIN, Maria do Rosário. Tecendo a teia do texto na escola. In: Curso de atualização para professores de 20 grau na área de língua portuguesa. Textos - Volume 1. Convênio Vital - UNESP - FUNDESP - SE/SP, Faculdade de Ciências e Letras de Araraquara, 1993b.

GREGOLIN, Maria do Rosário. A leitura na escola: formando corações e mentes. Revista Rumos, São Carlos, SP, v. 1, n. 1, p. 3-3, 1998.

GREGOLIN, Maria do Rosário. O literário no livro didático: esse obscuro objeto de leitura. Itinerários: Revista de Literatura, n. 17/18, 2001. Disponível em: <http://hdl.handle.net/11449/107370>. Acesso em: 6 nov. 2019.

GREGOLIN, Maria do Rosário. Análise do Discurso e mídia: a (re)produção de identidades. Comunicação, Mídia e Consumo (CMC) - Revista de Comunicação, São Paulo, v. 4, n. 11, p. 11-25, 2007a. Disponível em: <http://revistacmc.espm.br/index.php/revistacmc/article/view/105/106>. Acesso em: 6 nov. 2019.

GREGOLIN, Maria do Rosário. Formação discursiva, redes de memória e trajetos sociais de sentido: mídia e produção de identidades. In: BARONAS, Roberto Leiser (Org.). Análise do discurso: apontamentos para uma história da noção-conceito de formação discursiva. São Carlos, SP: Pedro e João, 2007b, p. 155-168. 
GREGOLIN, Maria do Rosário. O dispositivo escolar republicano na paisagem das cidades brasileiras: enunciados, visibilidades, subjetividades. Moara - Revista Eletrônica do Programa de Pós-Graduação em Letras, v. 1, p. 6-25, jan.-jun. 2015. Disponível em: <https://periodicos.ufpa.br/index.php/moara/article/view/2633>. Acesso em: 6 nov. 2019. DOI: https://doi.org/10.18542/moara.v1i43.2633

JENKINS, Henry. Cultura da Convergência. São Paulo: Aleph, 2009.

PÊCHEUX, Michel. O discurso: estrutura ou acontecimento. Campinas: Pontes, 1997.

Recebido em: 12 de fevereiro de 2020.

Aceito em: 17 de abril de 2020. 